EPiC Series in Education Science
Volume 3, 2020, Pages 108-114
Proceedings of the MIT LINC 2019 Conference

\title{
Use of Mobile Learning to Provide Inclusive Education in Low Resource Settings: Experiences from the Community mHealth Training Project, Kenya.
}

\author{
Gatotoh, Augustine Mwangi Ph.D ${ }^{1}$, Gakuu Christopher. M. Ph.D ${ }^{1}$ and \\ Keiyoro Peter. N. Ph.D ${ }^{1}$ \\ ${ }^{1}$ University of Nairobi, Kenya \\ Corresponding author: augmwa2002@gmail.com
}

\begin{abstract}
This study explores experiences in the use of mobile learning (mLearning) to train Community Health Volunteers (CHVs) in Kenya. It is drawn form a PhD research on mLearning adoption among CHVs enrolled on the mHealth platform. The study population was 3081 CHVs enrolled on the project. A sample of 354 participants was obtained for the survey. Questionnaires, key informant interviews and focus group discussions were triangulated during data collection. The findings show that mLearning was adopted across divergent learner characteristics. Further, mLearning presented opportunities such as a collaborative learning environment, accessibility, portability, and simplicity. The challenges included a limited depth of content, limited storage and battery life. This study concludes that mLearning can be used among diverse learners as long as effective support services are provided. The study recommends design of learner friendly mLearning platforms to enhance adoption. The study also recommends that mLearning is best situated in blended learning environments in order overcome some of the challenges experienced when mLearning is the only mode of delivery.
\end{abstract}

Key words: mLearning, mHealth, inclusive education, Community Health Volunteers, technology adoption.

\section{Introduction.}

Globally, there is a shortage of healthcare workers. According to WHO, estimates, there will be a shortage of 12.9 million healthcare workers by 2035 [1]. The WHO report emphasizes the need to 
address the shortfall. This shortage is more prevalent in developing countries. Moreover, the link between communities and healthcare is often weak in marginalized communities [1,2,3].

To address these gaps, mobile Learning (mLearning) has emerged as one of the tools to increase healthcare providers' access to training $[4,5,6]$. mLearning permits inclusivity across learner characteristics and physical learning environments enabling access to education any time anywhere $[6,8]$. Adoption of mLearning is described as the acceptance of mLearning across a population over time [6]. The need to leverage on the mobile subscriber rise in low resource countries is inevitable. By June 2018, the mobile service subscriptions in Kenya stood at 45.5 million marking an increase of 13.2 percent from 40.2 million recorded in June 2017 [9].

Additionally, Community Health Volunteers (CHVs) serve as links between communities and healthcare providers [1,6]. Since the Alma Ata Declaration in 1978, (CHVs) have been at the forefront of health services provision [1]. CHVs are involved in referrals, monitoring, reporting, community education and raising awareness on communicable diseases $[4,6,8]$. In Kenya, CHVs are expected to conduct monthly household visits within a defined catchment area of 20 households in rural areas and 100 households in urban areas [7]. They however, face challenges with resources and training $[6,7,8]$.

It is against this background that Amref Health Africa initiated the mHealth training project. The platform delivered key messages via SMS and Interactive Voice Recordings (IVR) focusing on topics aligned to Kenya's National CHW curriculum, including family planning, maternal and child nutrition and common diseases. The mLearning platform features included: Structured learning, multiple delivery modes, collaboration, assessment, learner support services, monitoring and feedback $[6,8,10,11]$ Figure 1.

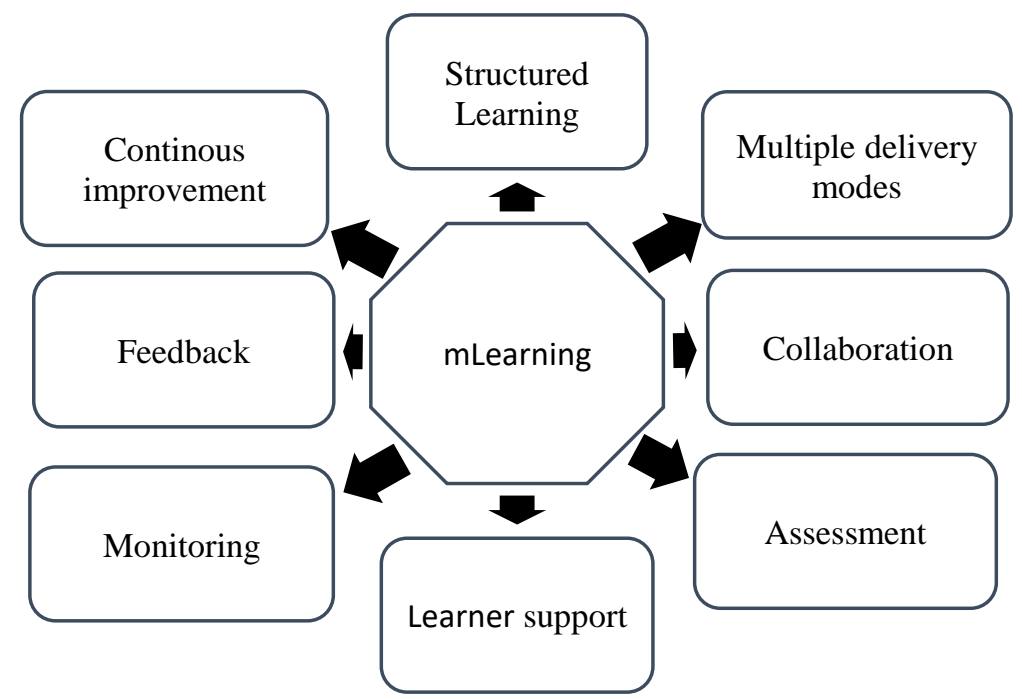

Figure 1: Features of the Mobile Learning Project

The current study is based on the aforementioned project. It seeks to demonstrate how mLearning was deployed successfully to end users with diverse characteristics.

\section{Literature Review}

There is a paradigm shift in the approach to CHW models. CHVs are now viewed as an integral and formal part of the health system, with reporting lines, training, supervision and feedback $[13,14,15,10]$. New mobile health technologies, mobile based expert support and mentorship systems are considerably improving efficiency of services provided. The emerging technologies are also 
transforming training and supervision methods for CHVs $[14,15]$. The emergence of mLearning has allowed easy access to educational opportunities while breaking the barriers of time and space $[6,16,10]$. It also helps learners combine formal and informal learning $[16,10]$ On the other hand mHealth solutions extends beyond training and education to disease management, point of care documentation and patient communication [17].

The paradox of mLearning, is that the physical attributes of the mobile devices are identified as potential enablers and barriers to successful adoption $[10,18]$. Limited processing power and reduced input capabilities are some of the barriers while portability of mobile phones is among the enablers of adoption [18]. The challenges notwithstanding, mLearning has great potential for inclusivity $[15,10]$. More however, require to be done to develop mLearning policies that promote accessibility for learners with disabilities [15].

Critical variables for adoption of mobile learning by diverse end users include learner characteristic $[6,8,10,11]$. Although mobile learning promotes inclusive education, different studies have produced dissimilar results on learner characteristics as determinants of technology adoption. Gender is for instance said to play an important role in technology adoption with the argument that men use technology due to its perceived usefulness while the major variable influencing women's decisions to adopt technology is ease of use [21]. It is however clear that determinants of adoption vary with learning environments.

This study is premised on the Unified Theory of Acceptance and Use of Technology (UTAUT). The Unified Theory of Acceptance and Use of Technology in part argues that individual characteristics and facilitating conditions are key factors in determining whether a technology will be adopted $[6,10,18]$. It is therefore, reasonable to argue that mLearning can be used to promote inclusive education provided end user characteristics and facilitating conditions are put into consideration at the design and implementation levels.

\section{Methodology}

The study was guided by the pragmatism paradigm. This paradigm was selected because it applies to mixed methods. It was assumed that the combination of qualitative and quantitative approaches would provide a more complete understanding of the research problem than either approach alone $[11,12,20]$. The study further utilized a decripto-explanatory survey research design. The design facilitated detailed description and analysis of the variables under study. Combined designs enabled the researchers to achieve optimal results $[11,12,20]$.

The unit of analysis for the research was CHVs enrolled for mLearning in the mHealth programme by Amref Health Africa. The study population was $3081 \mathrm{CHVs}$ enrolled on the project. Community Health Workers (CHWs) who served as supervisors of the CHVs served as key informants for this study. A sample of 354 participants was obtained for the survey. Questionnaires, key informant interviews and focus group discussions were triangulated during data collection. Data was collected from six counties stratified into rural, urban and nomadic settings.

\section{Results and Discussions}

The results focused on adoption of mLearning by CHVs with diverse learner characteristics. The demographic characteristics showed that the respondents were of a mixed gender and their age ranged from 24 to above 44 years. The focus for this paper is educational attainment, period of exposure as well as other qualitative responses on the same. 


\subsection{Educational attainment and adoption of mLearning}

The descriptive findings of this study showed that the participants' educational attainment ranged from basic education to bachelor's degree. Further, a Pearson Correlation was conducted as shown in Table 3.

Table 3: Educational Achievement and Adoption of mLearning

\begin{tabular}{ccc}
\hline & & Educational Attainment \\
\hline $\begin{array}{c}\text { Adoption of } \\
\text { mLearning }\end{array}$ & Correlation & $.150^{*}$ \\
& Coefficient & \\
& Sig. (2-tailed) & .012 \\
$\mathrm{~N}$ & 294 \\
\hline
\end{tabular}

The Pearson Correlation showed that educational achievement was positively and significantly correlated with adoption of mobile learning $(\mathrm{r}=.150 * \mathrm{p}<0.05)$. The weak positive correlation would indicate that while both variables tend to go up in response to one another, the relationship is not very strong. This demonstrates that although level of education as an entry behavior for mLearning is important, its contribution to adoption is weak. Thus the potential of mLearning for open access in terms diverse educational backgrounds. This can be further deduced from the interview with one of the CHVs. “... mLearning was easy for me...I did not complete secondary education but I found the organization of content very easy to follow...there were voice summaries which made it easy to understand ... chatting was free thus easy for us to learn from each other...there was a test before moving to the next topic... If I did not pass I could go back to the content and read again and again..." BL, a female $C H V$

The findings are consistent with other studies that suggested education experience may influence adoption on technology only to some extent [10,19]. The low level of significance shows that even where educational levels are diverse, mLearning can still be adopted and thus potential for inclusiveness.

\subsection{Period of exposure to mLearning}

The descriptive findings indicated that the participants were exposed to the mLearning programme for between 1 and 24 months. In addition, a Pearson Correlation was conducted. Table 4 shows the results of the Pearson Correlation for the period of exposure to mLearning on adoption of mLearning.

Table 4: Period of Exposure and Adoption of mLearning

\begin{tabular}{|c|c|c|}
\hline & & Period of exposure \\
\hline \multirow[t]{3}{*}{ Adoption of mLearning } & Correlation Coefficient & $.466^{* *}$ \\
\hline & Sig. (2-tailed) & .000 \\
\hline & $\mathrm{N}$ & 294 \\
\hline
\end{tabular}

The period of exposure to mLearning was positively and significantly correlated with adoption of mLearning $\left(\mathrm{r}=.466^{* *} \mathrm{p}<0.01\right)$. The moderate positive correlation implies that regardless of diverse backgrounds, the longer the learner is exposed to the mLearning platform the higher the chances of adoption of mLearning. This is consistent with [19] and [8] who found that the predictors of adoption vary with different experiences. 
“... at the beginning, it was difficult for most CHVs...as the mLearning programme progressed it became easy... they were able to complete topics much faster...this can be attributed to the support they received and simply getting used to mLearning..." TK, a Male, Community Health Worker (a supervisor who was a key informant)

\subsection{Opportunities and challenges}

From the in-depth interviews and focus group discussions, it emerged that mLearning has potential benefits and challenges for diverse learners in low resource settings. Following is transcript of one of the CHVs:

“... with mLearning, I was able to tend to my sheep and attend domestic chores at the same time...I could read the SMS...listen to voice...chatting on the platform was fun...challenges included, small screen, poor network, fast battery drainage...feedback meetings addressed some of the technical challenges ... we also called the help desk for support...this made mLearning easy" SM, a female CHV

From the focus group discussion, the opportunities are summed up as: (i) Collaborative learning environment- where learners were able to share experiences using the toll free SMS based chat platform. (ii) Learner-centered-mLearning enables learners to undertake their routine duties study at the same time. (iii) Accessibility- It is portable and also provided an opportunity for open learning with flexible entry behavior (iv) Trackable- It allowed for case management through the Learning Management Systems (LMS) (v) Simplicity-It was easy to adopt since it was modelled on the basic phone. The challenges included: Small screen size, limited storage space, draining of charge, limited content depth and poor network coverage in some geographical locations.

The findings are consistent with $[15,18]$ who find mLearning as having both advantages and disadvantages. The qualitative findings demonstrated that in spite of the challenges associated with mLearning, it promotes flexible learning environments. This is consistent with [4] who in a similar study found educational modules on mobile phones giving flexibility to Health Community Workers enabling access to learning content anywhere.

\section{Conclusions}

The study highlighted the need for a careful analysis of learner characteristics in the design of mLearning platforms. This is based on the fact that mLearning is highly personalized and therefore, its adoption is dependent on the end user. mLearning emerged as an effective mode of improving access to education for diverse learners as long as effective support services are provided. The study established that when designing support systems for mLearning, the learning context is as important as learner characteristics. The two must not be isolated from each other for optimum conditions of adoption of mLearning.

\section{Recommendations}

The study recommends that; (i) Policies should be focused on liberalization of telecommunication networks and lower tariffs mLearning initiatives; (ii) Learning institutions should design learner friendly mLearning platforms to enhance adoption; (iii) mLearning is best situated in blended learning environments in order overcome some of the challenges experienced when mLearning is the only mode of delivery. 


\section{Ethical consideration}

The National Council for Science, Technology and Innovation (NACOSTI) of Kenya conducted review of the study and approved it. Amref Health Africa also approved and granted authority to collect data form project staff and trained CHVs. All participants consented to take part in the study.

\section{References}

[1] WHO/3rd Global Forum, www.who.int/workforcealliance/forum/2013/hrh_commitments/en/.

[2] Adam MB, Dillmann M, Chen Mk, Mbugua S, Ndung'u J, et al. (2014) Improving Maternal and Newborn Health: Effectiveness of a Community Health Worker Program in Rural Kenya. PLOS ONE 9(8): e104027. https://doi.org/10.1371/journal.pone.0104027

[3] Miseda, M. H., Were, S. O., Murianki, C. A., Mutuku, M. P., \& Mutwiwa, S. N. (2017). The implication of the shortage of health workforce specialist on universal health coverage in Kenya. Human resources for health, 15(1), 80. doi:10.1186/s12960-017-0253-9

[4] Zolfo M. Iglesias D. Kiyan C, et al. (2010) Mobile learning for HIV/AIDS healthcare worker training in resource-limited settings. AIDS Res Ther. 2010; 7:35.

[5] O'Donovan J, Bersin A, O'Donovan C (2015) The effectiveness of mobile health (mHealth) technologies to train healthcare professionals in developing countries: a review of the literature BMJ Innovations 2015; 1:33-36.

[6] Gatotoh A.M, Gakuu C, M., Keiyoro, P, N, (2017) Learner Attitude and mLearning Adoption among Community Health Care Trainees, Kenya. International Journal of Current Research, Vol. 9, Issue,11, pp.60834-60838, November, 2017

[7] Aseyo, R E, Mumma J, Scott K, Nelima D, Davis E, Baker KK, Cumming O and Dreibelbis R, (2018) Realities and experiences of community health volunteers as agents for behavior change: evidence from an informal urban settlement in Kisumu, Kenya. Human Resources for Health201816:53 https://doi.org/10.1186/s12960-018-0318-4.

[8] Gatotoh A.M, Keiyoro, P, N, Gakuu C.M., (2017) Learner Characteristics: Antecedents for mLearning Adoption among Community Health Trainees, Kenya. International Journal of Scientific Research and Innovative Technology ISSN: 2313-3759 Vol. 4 No. 8; August 2017

[9] Gok (2018) Quarter-Four-sector-statistics-report-for-the-Financial-Year-2017-18(3)

[10] Gatotoh A.M, Gakuu C, M, Keiyoro, P, N, (2017) Learner Characteristics, Behaviour, Technology Use and Adoption of Mobile Learning Among Community Health TraineesAmref Health Africa, Kenya. Unpublished PhD thesis of the University of Nairobi

[11] Gatotoh A.M, Gakuu C, M., Keiyoro, P, N, (2018) Learner self-efficacy and mobile learning adoption among community health trainees, Kenya. International Journal of Science Arts and Commerce, Vol. 3 No. 2, February-2018

[12] Gakuu C.M., Kidombo J.H., Keiyoro N.P. (2018) Fundamentals of Research Methods: Concepts. Practice and Application. Aura Publishers, Kenya.

[13] Martin Oliver, Anne Geniets, Niall Winters, Isabella Rega \& Simon M. Mbae (2015) What do community health workers have to say about their work, and how can this inform improved programme design? A case study with CHWs within Kenya, Global Health Action, 8:1, DOI: 10.3402/gha.v8.27168

[14] Lewin S, Munabi-Babiqumira S, Glenton C, et al. Lay health workers in primary and community health care for maternal and child health and the management of infectious diseases (review). Cochrane Database Syst Rev 2010. 3: CD004015

[15] Singh P, Sachs JD. 1 million community health workers in sub-Saharan Africa by 2015. Lancet 2013; 382: 363-5. 
[16] Negas, M. C., \& Ramos, P. (2011, April). Critical Factors in the use of Mobile Learning by "Digital Natives" on Portuguese Teaching. In ICIME 2011-Proceedings of the 2nd International Conference on Information Management and Evaluation: ICIME 2011 Ryerson University, Toronto, Canada, 27-28 April 2011 (p. 333). Academic Conferences Limited.

[17] Istepanian R, Jovanov E, Zhang YT. Introduction to the special section on M-Health: beyond seamless mobility and global wireless health-care connectivity. IEEE Trans Inf Technol Biomed 2004;8:405-14

[18] Wang, Y. S., Wu, M. C., \&Wang, H. Y. (2009). Investigating the determinants and age and gender differences in the acceptance of mobile learning. British Journal of Educational Technology,40(1), 92-118

[19] Liao, H. L., \& Lu, H. P. (2008). The role of experience and innovation characteristics in the adoption and continued use of e-learning websites. Computers \& Education, 51(4), 14051416.

[20] Tashakkori, A., \& Teddlie, C. (2010). Putting the human back in "human research methodology": The researcher in mixed methods research.

[21] Wei, L., \& Zhang, M. (2008). The adoption and use of mobile phone in rural China: A case study of Hubei, China. Telematics and Informatics, 25 (3), 169-186. 